\title{
Araucaria as a Tool for Diagramming Arguments in Teaching and Studying Philosophy
}

\author{
GLENN ROWE \\ University of Dundee \\ FABRIZIO MACAGNO \\ Catholic University of Milan \\ CHRIS REED \\ University of Dundee \\ DOUGLAS WALTON \\ University of Winnipeg
}

\begin{abstract}
This paper explains how to use a new software tool for argument diagramming available free on the Internet, showing especially how it can be used in the classroom to enhance critical thinking in philosophy. The user loads a text file containing an argument into a box on the computer interface, and then creates an argument diagram by dragging lines (representing inferences) from one node (proposition) to another. A key feature is the support for argumentation schemes, common patterns of defeasible reasoning historically know as topics (topoi). Several examples are presented, as well as the results of an experiment in using the system with students in a university classroom.
\end{abstract}

Philosophical writing can be considered a form of argumentative discourse. Such a writer wants to convince her audience of readers or listeners by means of drawing logical inferences and presenting the logical development of her own ideas. Her aim is to provide her readers with reasons to come to accept a conclusion she reaches as reasonable and plausible. In philosophy, as in law and science, there is no indubitable conclusion established by the perfect proof (Descartes to the contrary). An argument for any conclusion needs to be evaluated in the light of the kind and nature of its premises, the strength of the inferential links to the conclusion from these premises, and of its possible criticisms or refutations. The importance of identifying, struc- 
turing and representing the components of philosophical and scientific reasoning was recognized by Finocchiaro, who in 1980, in his book Galileo and The Art of Reasoning, described some main passages in Galileo's arguments by visualizing them through diagrams. There is also a growing body of literature showing that argument diagramming, or "mapping" is being used in the philosophy classroom (Harrell 2005; Powers 2000; van Heuveln 2004), and that it is having a significant effect there (Twardy 2004; Van Gelder and Rizzo 2001). This paper explores a new software tool that supports students in employing features of argument diagramming that are not usually offered by such software, and investigates the tool's use in the classroom through a simple pilot evaluation study.

\section{Araucaria: Main Features}

Araucaria is a system of argument diagramming based on the Argumentation Markup Language formulated in XML (Reed and Rowe 2001, 2004). It is available at no cost on the Internet. ${ }^{1}$ The user can load a text file comprising the text of the discourse, and it will appear in the left-hand box of the Araucaria interface. The nodes of the diagram (indicated by alphabetical letters) are formed by highlighting sections of the argument text with the left button of the mouse and clicking on the right pane. The corresponding text will appear on the bottom line when nodes are selected. Support relationships are then created by dragging a line from one node to another. When the left button is released, an arrow representing the connection will appear. Premises can be arranged in serial, convergent or linked structures, and missing assumptions can be inserted in an enthymeme, marking the inserted text as an unstated premise or conclusion (it appears as a grey node). Araucaria also supports the insertion of refutations: it is possible to represent counter-arguments defeating conclusions or premises.

It is also possible to insert an evaluation of a premise in order to indicate its strength, or to mark an inference arrow to show the strength of its support for a conclusion. In the case of refutations, it is possible to compare the force of opposite arguments. Regarding the use of Araucaria diagrams in other programs (such as word processors), not only the summary diagram but also its full text version (including the text corresponding to the nodes) can be visualized and saved as an image. Figure 1 shows what an Araucaria window looks like:

In this example, the argument from premises $\mathrm{B}$ and $\mathrm{C}$ to conclusion A is convergent, whereas the argument from premises $F$ and $G$ to conclusion $\mathrm{E}$ is linked. The example shows how arguments are combined to form a chain of argumentation (serial arguments). The so-called divergent argument, in which a single premise supports two different 


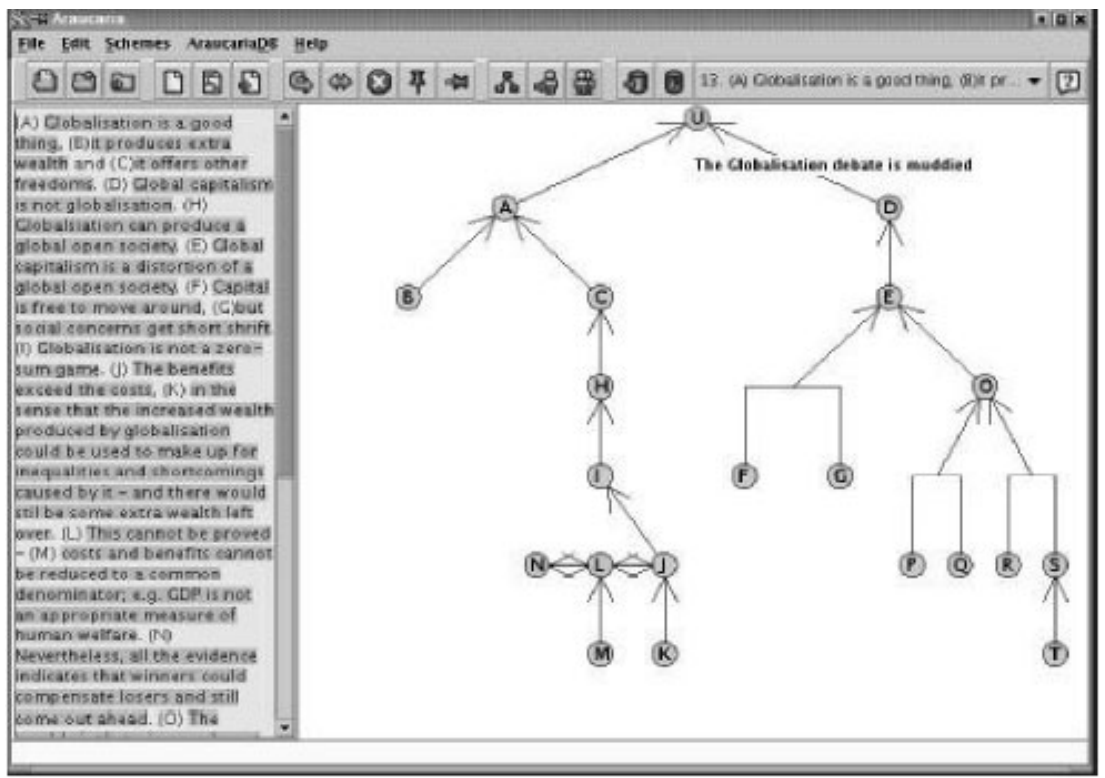

Figure 1. Araucaria screenshot

conclusions, is not represented in Araucaria. Also, circular arguments are not represented in Araucaria. The argumentation always has the form of a tree structure.

\section{Using Araucaria to Enhance Critical Thinking in Philosophy}

Finocchiaro in Galileo and the Art of Reasoning (1980) used diagrams to represent Galileo's arguments and to study critiques of them. The graphs used as argument diagrams by Finocchiaro are useful to show the relations between premises and conclusions, but the nature of the relations between them are not represented. The following example, from Finocchiaro (1980: 377), is diagrammed below using Araucaria. It represents the teleological argument, one of the main points of Galileo's critique of the canonical conception of the world.

(A) Changes among terrestrial bodies enhance the perfection of the earth; for example, (B) living organisms are more perfect than dead ones, and (C) gardens more than deserts. But, (D) heavenly changes would render heavenly bodies imperfect, since (E) heavenly changes would be of no use or benefit to man, and hence $(F)$ they would be superfluous; therefore, $(\mathrm{G})$ unchangeability would enhance the perfection of heavenly bodies. Therefore, $(\mathrm{H})$ heavenly bodies are unchangeable. This is also shown by the fact that, since (I) heavenly changes would be superfluous, and since $(\mathrm{J})$ nature does nothing in vain, $(\mathrm{K})$ there cannot be any heavenly changes. 
In addition, we can insert the following missing premises.

(L) Superfluity is relative to human needs

(M) Living organisms can change while dead ones cannot

(N) Gardens can change while deserts cannot

(O) Superfluity is cause of imperfection

(P) If something is of no use or benefit to man, it is superfluous

(Q) Opposite causes or properties cause opposite effects

An Araucaria diagram representing the entire structure of this argument is given below.

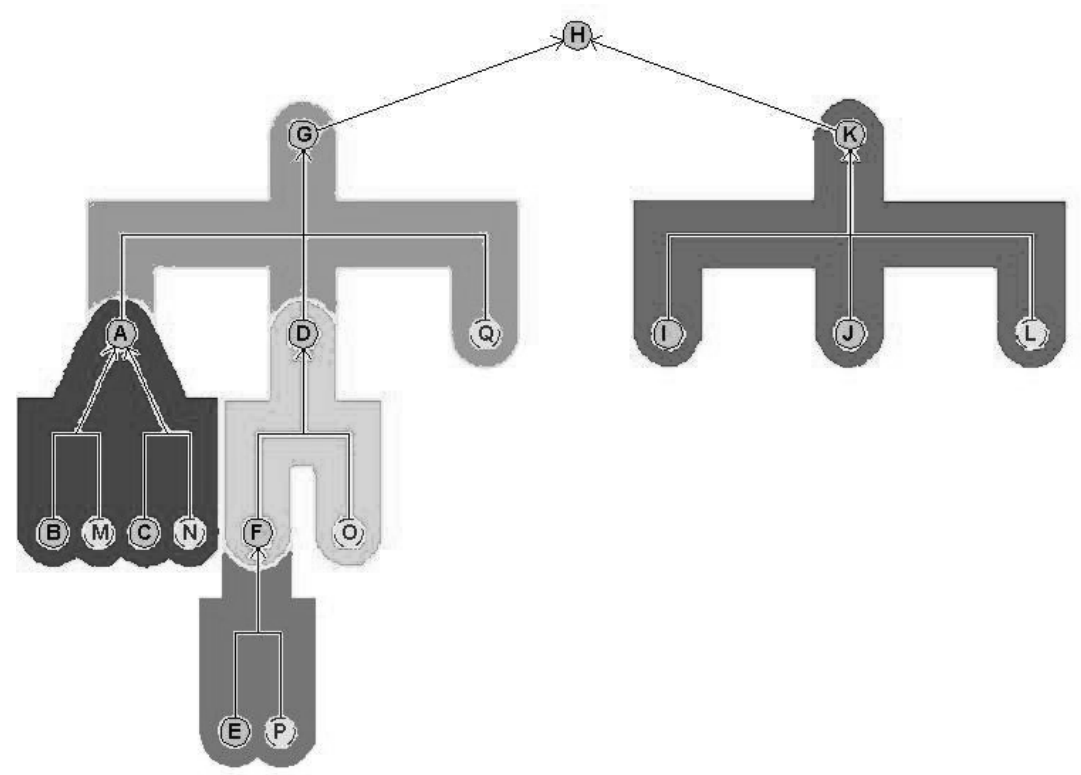

Figure 2. Araucaria analysis of a part of Galileo's argument

In this diagram it appears that the conclusion depends on two independent lines of argument, both supported by linked premises. The latter are represented by the connected lines in which all premises are required in order to support the conclusion. If only one premise is omitted, the whole argument is defeated. The analysis of the missing premises points out the weak points of the argument. Premise P (If something is of no use or benefit to man, it is superfluous) and premise L (Superfluity is relative to human needs) are particularly controversial. They are implicit, and taken for granted. For this reason it is necessary to examine the whole structure of the argument in order to assess their role. The whole support given to the conclusion depends on these two 
premises. For this reason, Galileo moved his attack to address them, respectively with rebuttals (R) and (S) (Finocchiaro 1980: 377).

(R) Man should not be regarded as the sole creature for whose sake and benefit the whole universe exists

(S) It is not acceptable that nature brings nothing into existence which is superflous from the point of view of human needs

These first of these two rebuttals is diagrammed in Figure 3 (this time showing the "full text" for convenience).

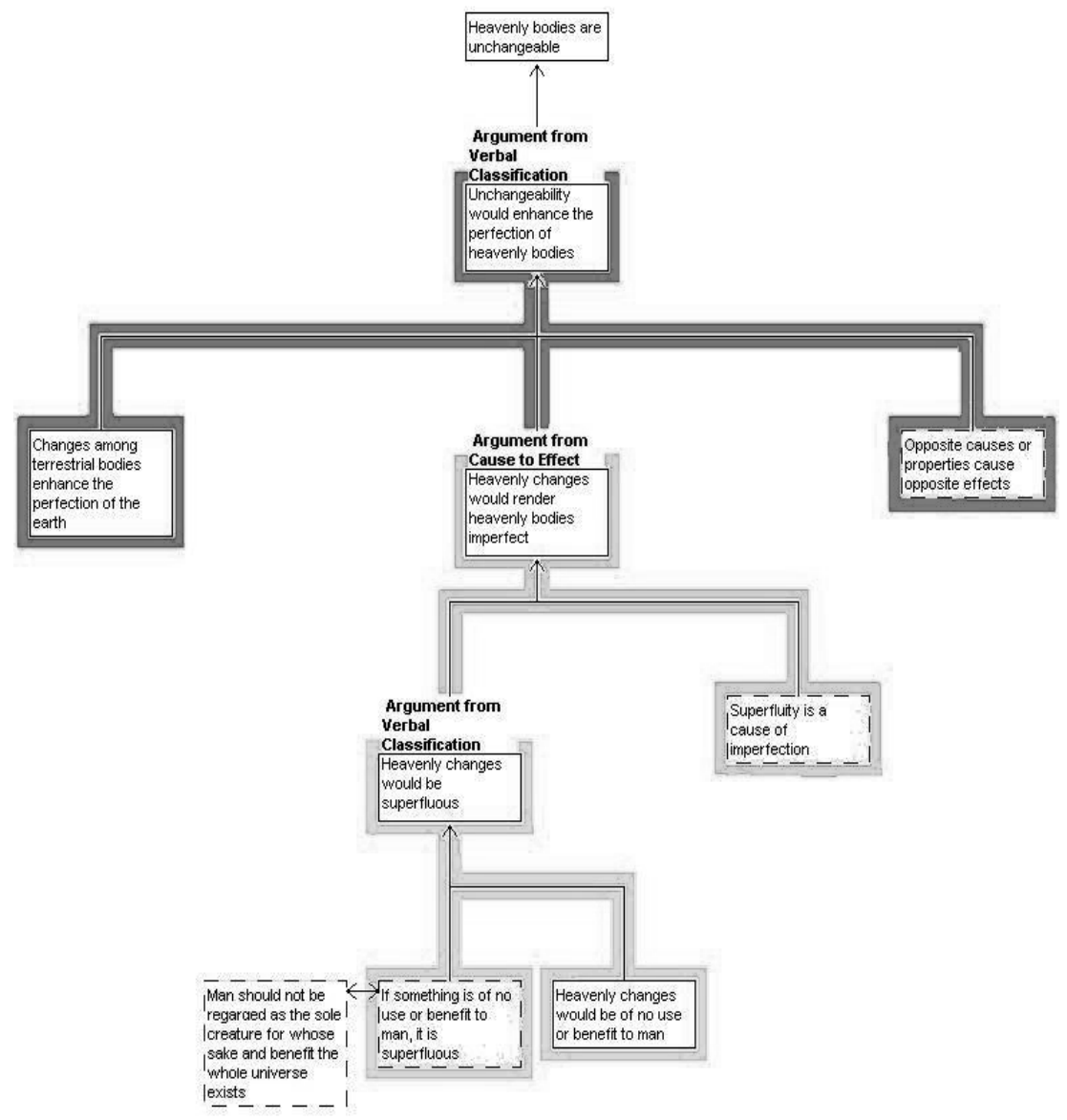

Figure 3. Araucaria full text analysis of the first refutation 


\section{Argumentation Schemes}

One of the unique features of Araucaria is its support for argumentation schemes and their identification in diagrams to show the type of inferential relations between premises and conclusions. In any kind of argumentative discourse it is important to understand the quasi-logical links in order to evaluate the plausibility and the fallaciousness of the passage itself. Analyzing the structure of the reasoning allows the user to more thoroughly assess the support for a conclusion given in an argumentative text. Deductive and inductive forms of argumentation are supplemented by argumentation schemes for plausible reasoning (Walton 1996a). The concept of a plausible link as opposed to a necessary or logical one has its roots in the account of dialectic and rhetoric given by Aristotle. The plausible structures of the presumptive argumentation schemes allow conclusions to be derived from the premises by defeasible inferences. They correspond to what were historically known as topoi, or in the middle ages, under the name of loci. With the rediscovery of argumentation in the last fifty years, the importance of plausible reasoning and topoi has been reconsidered. Under the name of argumentation schemes, these ancient dialectical and rhetorical warrants have been examined by Perelman (1969), Toulmin (1958), Kienpointner (1992), van Eemeren (1992), Walton (1996a) and others. Such recent studies have integrated topical argumentation schemes in an approach to plausible reasoning that analyzes fallacies in relation to their necessary conditions of correct use provided by schemes. It has been shown how, for each scheme, a list of requirements the argument must have in order to be valid can be formulated. Additional requirements are formulated as conditions regarding the answering of critical questions. Thus according to the kind of infractions to conditions for a scheme, or for responding to it, an argument can be evaluated as unreasonable, fallacious or weak, depending on the details of how it was used in a given instance.

For example, the argument from expert opinion has the following scheme and necessary conditions (Walton 2002: 49-50).

\section{Scheme for Argument from Expert Opinion}

MAJOR PREMISE: Source $E$ is an expert in subject domain $S$ containing proposition $A$.

MINOR PREMISE: $E$ asserts that proposition $A$ is true (false)

CONCLUSION: $A$ is true (false)

\section{Critical Questions}

Expertise Question: How credible is $E$ as an expert source?

Field Question: Is $E$ an expert in the field that $A$ is in?

Opinion Question: What $\operatorname{did} E$ assert that implies $A$ ? 
Trustworthiness Question: Is E personally reliable as a source?

Consistency Question: Is A consistent with what other experts assert?

Backup Evidence Question: Is E's assertion based on evidence?

This type of schematic evaluation by comparison of the argument with its critical questions is a powerful tool to assess the strength or weakness of an argument. The analysis of arguments through schemes is useful in every discipline, like philosophy, law, or the sciences. In every field, proofs and justifications often fall into the realm of plausible reasoning rather than deductive or inductive logic (pure mathematics possibly excepted). In such instances, fallacies and weak arguments can mistakenly be taken as strong or even conclusive ones. Argumentation schemes, as instruments for argument identification, analysis and evaluation, are therefore one of the most useful tools Araucaria provides. In particular, one of their most interesting applications may be in teaching philosophy.

\section{Utilising Araucaria's Schemes in Teaching Philosophy}

These diagrams make clear the role and the scope of refutations in the structure of the argument. Argumentation schemes, as shown, are helpful to guide in reconstructing the missing premises. After determining the relationship that links the premises to the conclusion it becomes possible to understand how the missing elements should be filled in to complete the analysis.

Diagrams are not only useful to represent and clarify the thesis of an argument and the objections to it, but also to examine in depth the plausible inferential steps supporting the thesis. Establishing such inferential steps can help in identifying and analysing a given argument and evaluating chain of reasoning in it. Using this method we can help students better grasp the chain of reasoning in the famous Cogito ergo sum argument of Descartes (see Figure 4, p. 118).

In this case, in our analysis of the argument, the inferential link between the premises and the final conclusion is represented by the scheme for the argument from verbal classification. If subject $\mathrm{x}$ is characterized by the property, or predicate 'thinking,' it is characterized also by the property 'existing.' On the other hand, the support given to the premise 'I think' is implicit in Descartes's philosophy. The act of doubting thinking presupposes the act of thinking itself. Thus the conclusion follows from argument from verbal classification. From this brief analysis, it is possible to better understand the argumentation structure of Descartes's reasoning.

The following example concerns the teaching of critical thinking skills in the philosophy of history. Consider the following example of an argument, 'There are no known instances of Romans being awarded medals 


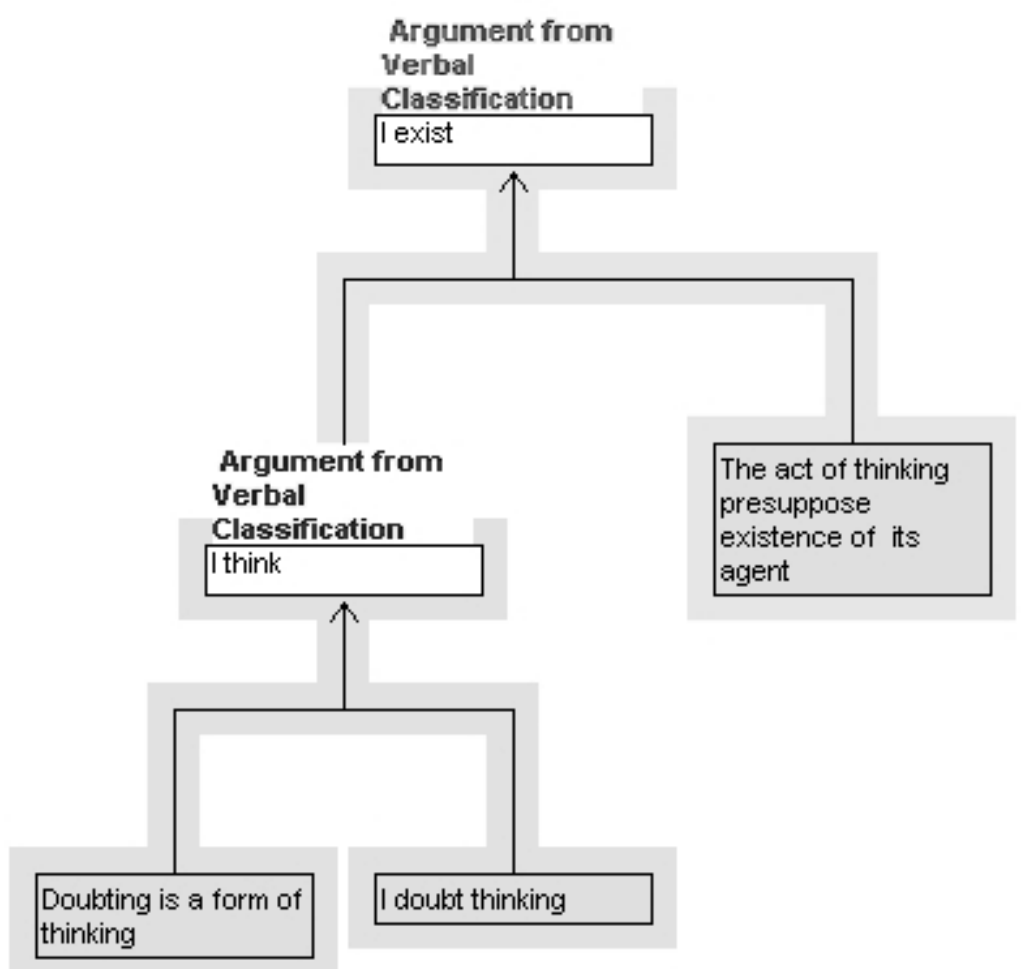

Figure 4. Araucaria full text scheme-based analysis of cogito ergo sum

for bravery in battle posthumously, therefore the Romans did not award medals for bravery in battle posthumously.' This Roman medals example is an instance of argument from ignorance, as it is called in philosophy. It is also known as the lack of evidence argument or negative evidence in science, and the ex silentio argument in history. Suppose a student were to encounter the Roman medals argument in reading a history book. It looks like a weak argument, because it seems to be based on no evidence at all, or lack of evidence. But it is an enthymeme, and if the student could fill in the missing premise, she could see that the absence of evidence is itself a kind of evidence, that could be supported by the collection of further evidence. The scheme is helpful for this purpose.

The account of the argumentation scheme for argument from ignorance (Walton 1996b: 254) shows that this form of argument has two premises. $A$ is a variable for propositions (statements).

Argumentation Scheme for Argument from Ignorance

If $A$ were true, $A$ would be proved to be true by some positive evidence. 


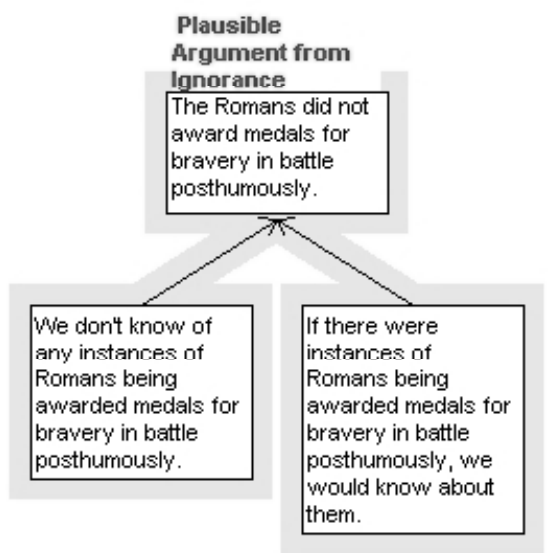

Figure 5. Full text diagram of the Roman medals example.

There is no such positive evidence for $A$.

Therefore $A$ is false.

The argument has what appears to be a modus tollens form. The first premise is a conditional. In the Roman medals case, the scheme could be used to fill in the conditional premise, as shown in the Araucaria diagram in Figure 5.

The idea is that, in this case, the student could use the scheme to recognize the implicit conditional premise. Then she could realize that the conditional premise could be supported by further evidence of historical searching and collection of data that has taken place. There are written records of battles, and there are also many Roman tombstones that have been studied. We would see evidence of posthumous medals in these records and on theses tombstones, if they were awarded. Thus the student can see that even thought the reasoning in the case is based on argument from ignorance, and is a presumptive and inconclusive sort of argument, it still has some strength as an argument, and can be supported by evidence. The student can realize that in order to evaluate the argument properly, one needs to focus on this implicit premise, and see what sort of evidence backs it up.

To sum up, Araucaria can be considered a useful means to both teach and learn philosophy. In teaching, by diagramming philosophers' arguments it becomes much easier to explain and summarize the most important points in their theories. From the students' point of view, building argument diagrams constitutes an important exercise of critical reflection on a given passage, and provides a helpful strategy of organizing and summarizing the main steps of reasoning in it. Both 
analysis and synthetic organization are improved by visualization. Araucaria, as used in philosophy, can provide an exercise for active learning by reconstructing missing premises and determining the nature of inferential links in an extended chain of argumentation. Such an exercise of reflection and inquiry is allied with aim of the discipline of philosophy itself.

\section{An Experiment in Teaching Araucaria}

For an advanced analysis of argument, Araucaria is one of the most developed diagramming system with a unique set of features. Its roots in plausible reasoning theory, its focus on argumentation schemes, and its account of inferential passages provided through precise graphs, show not only the weight and function of each premise but also the implicit assumptions needed to correctly evaluate the argumentation supporting a conclusion

For these reasons, Araucaria has been experimentally introduced in Walton's Argumentation course as a required tool used to draw the argument diagrams that are needed in the assignments. One purpose of introducing this software on a trial basis was to test the effective capacity for the software to aid in developing critical skills in the analysis of argumentation. The students, after introductory classes on argumentation and tutoring on Araucaria use in lab sessions, were confronted with the task of constructing argument diagrams. In the second assignment of the course students were required to draw diagrams of enthymemes in order to identify the missing premises and any argumentation schemes justifying the inferences. In the third assignment, the diagrams were used to represent the structure of examples of arguments fitting various emotional appeals, like appeal to pity, personal attack and appeal to force. The task was to use the diagrams as part of the evidence required to evaluate the critical questions matching the schemes and offer reasons why the passage might be considered fallacious or not.

In all these assignments, Araucaria provided the students with an instrument to identify and structure the chain reasoning found in an actual case of argumentation. To carry out these tasks, the students were required to identify premises, identify partial and ultimate conclusions, and to distinguish between linked and convergent arguments. The diagram provides an orderly and visual format for organizing an argument analysis, enabling the user to structure the argumentation in a given case as a structured sequence of steps, drawn as nodes and arrows. In this way the student can recognize the similarities of structure, for example in judging relevance, in different examples of actual argumentation, and visualize the structure by means of spatial positions, of nodes and 
arrows leading towards a conclusion. Moreover, the software allows the student to concretely represent the implicit assumptions and connect them with their specific role in supporting a thesis.

In addition to identifying the basic pattern of an argument, in order to construct the diagram it is necessary for students to learn to select the appropriate argumentation schemes for the inferential steps. The user, after highlighting the arrows, can choose between twenty-six schemes that can be deployed to justify the link (these twenty-six are taken from Walton 1996a, and form one popular "schemeset" that accompanies the software: there are a number of different such schemesets reflecting different current theoretical approaches, and instructors are also able to construct their own). This feature enhances, in particular, two skills. First, there is the skill of evaluating which premises constitute a coherent set for supporting the conclusion. Second, there is the skill of individuating the appropriate form of an argument and consequently testing and improving the relative acquired knowledge. Rarely, in fact, are argumentation schemes constituted only by one premise. Often, explicit statements must be linked into longer chains of argumentation, filled in with reconstructed missing assumptions. It is necessary for the student to know the main features of the schemes in order to make appropriate choices.

In the assignment on fallacies, the focus is on another aspect of dialectical skills: the critical evaluation of arguments. In Walton's theory, almost every fallacy is associated with a particular argumentation scheme, sharing the main structure but not necessarily respecting its necessary characteristics, or maintaining the right balance with respect to its matching critical questions. The student has the task of giving reasons to distinguish between the fallacious argument and reasonable use of an argument in a given case. What needs to be stressed is these are practical skills, because the student is dealing with a real argument given in a text of discourse in some source, like an article found in an article in a newspaper or magazine article.

To sum up, Araucaria was used in this experimental setting as a teaching tool to represent the structure of arguments and as a learning instrument to test and apply what has been studied. The students were given the opportunity of practicing the critical abilities learnt during the course by choosing the examples selected for study. The method employed can thus be seen as an interactive tool, providing a hands-on way to learn pragmatically.

\section{Students' Feedback}

To gauge initial impact of the software, a small pilot study was conducted to gather student feedback amongst a class of twenty-two. The 
focus of the study is purely exploratory, and does not aim to compare with large scale quantitative studies that measure pre and post performance against a well known target (such as the CCTST or Ennis-Weir). The aim of this pilot is to assess (a) whether or not the adoption of

\begin{tabular}{|c|c|c|c|c|c|c|}
\hline & & High & Medium & \begin{tabular}{|c|} 
No \\
opinion
\end{tabular} & Low & Absent \\
\hline 1 & $\begin{array}{l}\text { Usefulness of learning about } \\
\text { Araucaria in the argumenta- } \\
\text { tion course }\end{array}$ & $57 \%$ & $22 \%$ & $7 \%$ & $14 \%$ & \\
\hline 2 & $\begin{array}{l}\text { Enjoyment in using Arau- } \\
\text { caria to diagram arguments }\end{array}$ & $43 \%$ & $36 \%$ & $7 \%$ & $14 \%$ & \\
\hline 3 & $\begin{array}{l}\text { Future usefulness of Arau- } \\
\text { caria for analyzing argu- } \\
\text { ments or for other purposes }\end{array}$ & $14 \%$ & $62 \%$ & $8 \%$ & $8 \%$ & $8 \%$ \\
\hline 4 & $\begin{array}{l}\text { Help given by learning Arau- } \\
\text { caria in improving personal } \\
\text { skills in the critical analysis } \\
\text { of argumentation }\end{array}$ & $43 \%$ & $36 \%$ & $7 \%$ & $14 \%$ & \\
\hline 5 & $\begin{array}{l}\text { Importance of keeping Arau- } \\
\text { caria as a regular part of the } \\
\text { argumentation course }\end{array}$ & $50 \%$ & $29 \%$ & $7 \%$ & $14 \%$ & \\
\hline 6 & $\begin{array}{l}\text { Necessity of extra help } \\
\text { learning Araucaria }\end{array}$ & $22 \%$ & $34 \%$ & $11 \%$ & $5 \%$ & $28 \%$ \\
\hline 7 & $\begin{array}{l}\text { Necessity of practice/lab } \\
\text { sessions on learning to use } \\
\text { Araucaria outside the regular } \\
\text { classes }\end{array}$ & $54 \%$ & $16 \%$ & & $15 \%$ & $15 \%$ \\
\hline 8 & $\begin{array}{l}\text { Possible application of Arau- } \\
\text { caria as a device helpful in } \\
\text { learning better writing and } \\
\text { argumentation skills }\end{array}$ & $21 \%$ & $72 \%$ & & $7 \%$ & \\
\hline
\end{tabular}

Araucaria in this class is warranted, (b) whether or not a larger scale, more rigorous evaluation is warranted.

The feedback of the experiment, even if limited to the students in this one class, is indicative of the help Araucaria can provide and of the problems students may encounter in learning how to use it. The survey below, based on the survey of the students in the class, has been structured in two parts, a questionnaire to test the students' response to Araucaria and a space for their comments on how it might be improved. The first five questions aim to evaluate the perceived efficacy of Araucaria and the students' approval or disapproval of its introduction as a required part of the course. Questions 6 and 7 were designed to highlight the difficulties in learning Araucaria that may have been experienced, while the last explores perceptions concerning whether Araucaria can help in improving skills other than critical analysis. These are the results, expressed in percentages. 
From the questionnaire we can observe that the students' response to the experimental use of Araucaria in teaching was positive: almost 80 percent of them considered the program enjoyable, useful and important for the purposes of the course. On the other hand, 57 percent of the students had problems in learning the software, and the 80 percent of them considered seminars and labs on Araucaria outside regular classes necessary. Note however that the percentage not recognizing the usefulness of the program in learning better writing and arguing was minimal.

\section{Limitations and Future Directions}

Self evidently, these results are very preliminary, but nevertheless they offer some interesting insights and indicate potential directions for future work in both evaluation and software development. The qualitative feedback elicited by the study indicated that one of the first stumbling blocks can be installation, for although the software is made available on university machines, many students wanted to use it on their own computers. With help, the problems were never insurmountable, but to scale, the installation process must be simpler. As Harrell (2005) has pointed out, the requirement for text to be available at the outset can present a challenge in some contexts. Though the problem can be circumvented by using the "missing premise" option, Araucaria's focus on analysis rather than construction of argument is sometimes at odds with what the instructor may want to achieve. Similarly a few comments indicated that students sometimes wanted to override the default visual layout. Other useful comments included confusion over toolbar icons, a desire to construct analyses in 'full text' mode, a lack of clarity in changing sets of schemes, an opportunity for selecting schemes through a taxonomy, and the need for handling divergent argument.

The pilot study was founded upon Araucaria version 2.0, released in 2003. The feedback elicited from the study has been utilised in guiding development of version 3.0, which was released in May of 2005 and which tackles most of the outstanding issues, as well as introducing functionality to handle different styles of argument diagram notations (such as Toulmin diagrams). The predominantly positive experiences of the students warrants both using Araucaria in the Winnipeg class in the future, and also conducting a larger scale study. It will be important to explore student experiences not only in courses in philosophy but also more general cross-disciplinary courses, such as the course at Dundee on Critical Thinking that is offered to humanities, science and engineering students. This will lay a foundation for more rigorous investigation of the objective impact that the software has, which will need to harness a wide variety of assessment techniques. 


\section{Note}

1. The Araucaria software can be downloaded from araucaria.computing.dundee .ac.uk.

\section{Bibliography}

van Eemeren, Frans H., and Rob Grootendorst. 1992. Argumentation, Communication and Fallacies (Hillsdale, N.J.: LEA).

Finocchiaro, Maurice. 1980. Galileo and the Art of Reasoning (Dordrecht: Reidel).

Harrell, Maralee. 2005. "Using Argument Diagramming Software in the Classroom," Teaching Philosophy 28:2: 163-77.

van Heuveln, Bram. 2004. "Reason!Able: An Argument-Diagramming Software Package," Teaching Philosophy 27:2: 167-72.

Kienpointner, Manfred. 1987. "Towards a Typology of Argumentation Schemes," in Argumentation: Across the Lines of Discipline (Dordrecht: Foris), 275-87.

.1992. Alltagslogik: Struktur und Funktion von Argumenationsmustern (Stuttgart: Fromman-Holzboog).

Perelman, Chaim, and Lucie Olbrechts-Tyteca. 1969. The New Rhetoric (Notre Dame, Ind:: University of Notre Dame Press).

Powers, Jonathan. 2000. "Diagramming Aristotle's Nicomathean Ethics," Teaching Philosophy 23:4: 343-52.

Reed, Chris, and Glenn Rowe. 2001. "Araucaria: Software for Puzzles in Argument Diagramming and XML," Department of Applied Computing, University of Dundee Technical Report.

2004. "Araucaria: Software for Argument Analysis, Diagramming and Representation," International Journal of AI Tools 14:3-4: 961-80.

Toulmin, Stephen. 1958. The Uses of Argument (Cambridge, Cambridge University Press).

Twardy, Charles. 2004. "Argument Maps Improve Critical Thinking," Teaching Philosophy 27:2: 95-116.

Van Gelder, Tim, and Alberto Rizzo. 2001. "Reasonable Across the Curriculum," in 2001: Is IT an Odyssey in Learning? Proceedings of the 2001 Conference of ICT in Education Victoria.

Walton, Douglas. 1996a. Argumentation Schemes for Presumptive Reasoning (Mahwah, N.J.: Erlbaum).

1996b. Arguments from Ignorance (University Park: Penn State Press).

1997. Appeal to Expert Opinion (University Park: Penn State Press).

2002. Legal Argumentation and Evidence (University Park: Penn State Press).

Glenn Rowe, Department of Applied Computing, University of Dundee, Dundee DD14HN, Scotland; glenn@computing.dundee.ac.uk

Fabrizio Macagno, Department of Linguistics, Università Cattolica del Sacro Cuore di Milano, Milano, Italy; fabriziomacagno@hotmail.com

Chris Reed, Department of Applied Computing, University of Dundee, Dundee DD1 4HN, Scotland chirs@computing.dundee.ac.uk;

Douglas Walton, Department of Philosophy, University of Winnipeg, Winnipeg, Manitoba, R3B 2E9 CANADA; d.walton@ uwinnipeg.ca 